\title{
Independent Effects of Paternal Involvement and Maternal Mental Illness on Child Outcomes
}

\author{
Paula Allen-Meares \\ University of Illinois at Chicago \\ Juliane Blazevski \\ University of Michigan \\ Deborah Bybee \\ Michigan State University \\ Daphna Oyserman \\ University of Michigan
}

\begin{abstract}
Previous research suggests that serious maternal mental illness is associated with adverse youth outcomes. However, this research is of limited ability to inform appropriate social work and social policy responses for at least two reasons. First, it is based on samples that are not racially or ethnically diverse and that do not target low-income families; second, it does not examine whether differences in the level of father involvement or the severity of maternal mental illness matter. This study involves a low-income, racially and ethnically diverse sample of mothers with a serious mental illness and their 11-18-year-old children and examines parent effects on youths. Fathers were in contact but mostly were not livein parents. Structural equation modeling yields three key results: better maternal functioning and more paternal involvement predict better academic outcomes; less paternal involvement and more maternal health problems predict higher youth-reported affiliative skills; and more paternal involvement predicts less youth-reported problem behavior.
\end{abstract}

Women with a range of serious mental health problems raise children and are about as likely as other women to become pregnant (for a review, see Kahng et al. 2008). ${ }^{1}$ However, their pregnancies are less likely to be planned, and when women with a serious mental illness (SMI)

Social Service Review (March 2010).

(c) 2010 by The University of Chicago. All rights reserved.

0037-7961/2010/8401-0006\$10.00 
become pregnant, they are less likely to marry the infant's father. ${ }^{2}$ Moreover, the fathers themselves are likely to have mental health problems, and the couple is at greater risk of breakup than are other couples (for a review, see Mowbray et al. 1995). The available evidence suggests both that mothers with SMI are more likely than other mothers to engage in poor parenting practices (for a review, see Oyserman et al. 2000) and that the teenaged children of mothers with SMI are at risk of both socioemotional and cognitive problems. Specifically, negative child socioemotional consequences are associated with maternal diagnosis and symptoms of depression (for reviews, Downey and Coyne 1990; Gelfand and Teti 1990; Beardslee, Versage, and Gladstone 1998; Goodman and Gotlib 1999), and negative child cognitive consequences are associated with maternal SMI and schizophrenia (for reviews, see Oyserman et al. 2000; Mowbray and Oyserman 2003).

The accumulated evidence implies that social work intervention is needed to reduce the risk that maternal SMI poses for youths. Closer inspection of the evidence reveals, however, that this literature provides an insufficient basis for targeting intervention for two reasons. First, because samples have been from predominantly white and middle-class families, research does not consider outcomes of children from lowincome and racially and ethnically diverse families (for an exception, see Foster et al. 2008). This omission means that the estimated effects from prior literature may under- or overestimate the impact of maternal SMI on outcomes relative to other problems such as poverty and institutionalized racism. Second, research does not provide a clear prediction about the impact of the father in the context of maternal SMI; here as well effects may differ among low-income and racially and ethnically diverse families (Mowbray et al. 2005). An emerging literature identifies small but statistically significant and positive effects of father involvement (Amato and Gilbreth 1999). However, there is a dearth of studies that consider father involvement in combination with maternal SMI.

Recall that maternal SMI is associated with a higher risk of an unplanned pregnancy occurring in the context of an unstable relationship with a partner with mental health problems of his own so that fathers are less likely to live with the mother and child over time (e.g., Mowbray et al. 1995). Each of these factors is likely to undermine the positive effect of father involvement, so it is important to consider how father involvement matters in the context of maternal SMI. When both maternal functioning and paternal involvement effects are considered simultaneously, it is possible that both maternal SMI and father involvement affect children's outcomes. Alternatively, it is possible that one effect overrides the other. Thus, father involvement may override effects of differences in maternal functioning and symptoms related to SMI, so that maternal SMI may no longer be associated with negative out- 
comes for children. Conversely, maternal SMI may override effects of differences in father involvement so that father involvement is no longer associated with positive outcomes for children.

Social service providers working with children from families in which the mother has an SMI need empirical support that helps them decide among possible treatment plans that differ in how much children, mothers, and fathers are targeted for intervention. The current study considers a number of relevant possibilities. First, it considers whether father involvement has positive effects for youths whose mother has an SMI. It considers these possible effects both for fathers who live with the youth and for fathers who do not. Second, it considers whether father involvement has positive effects only when fathers actually live in the home. Third, it considers whether father involvement and maternal SMI interact such that father involvement only matters in some conditions.

Each of these possibilities is consequential for social work intervention. If father involvement is found to have positive effects that are separate from living arrangement, social workers could assess whether a particular youth has contact with his or her father and work to increase involvement or provide alternative supports when fathers are not involved. Such a finding would also suggest that policies should attempt to facilitate father involvement with youths in this population. If father involvement is found to have positive effects that are contingent on living arrangement, the social work intervention plan would need to take that into account. If convincing the father to coreside with the mother and child is impossible, social work intervention and policy would then need to focus on increasing other forms of support to mothers and youths. If father involvement is found to have positive effects that are contingent on maternal functioning, this also would be relevant for social work intervention. For example, father involvement might compensate for low maternal functioning or may only matter when maternal functioning reaches a certain level.

The limited available evidence suggests that involvement of nonresidential fathers may not be significantly associated with improved youth outcomes. In analyses of data from a national community sample in the United States, father involvement was found to reduce the likelihood that youths would have internalizing (e.g., self-blame, anxiety) and externalizing (e.g., behavioral) problems. Analyses of the conditions under which father involvement matters reveal that the positive effect of father involvement is particularly noticeable when mothers do not have symptoms of depression (Chang, Halpern, and Kaufman 2007) and when fathers are resident and highly involved (Carlson 2006). Two prior studies included mothers with a diagnosed mental health problem (Brennan, Le Brocque, and Hammen 2003; Hammen, Brennan, and Shih 2004). Both studies suggest that father involvement is helpful. However, in both studies the sample is composed of white Australian, two-parent 
families (in Australia). The studies compared internalizing and social functioning outcomes of two groups of youths: those whose mothers had a current or lifetime diagnosis of major depression or dysthymic disorder and those whose mothers had no history of these disorders. In these studies, maternal depression was associated with more child internalizing, and father involvement was associated with less child internalizing and better child social functioning. However, generalizability to populations in need of social work intervention is unclear because the samples were comprised of white and two-parent families and because mothers had only depressive disorders, whereas social workers work with diverse families in which fathers are not always present and mothers have a variety of SMIs.

To address these gaps the current study specifically targets effects of maternal SMI (schizophrenia, bipolar, and affective disorders) and father involvement on a variety of youth outcomes in a social work-relevant population (low-income, racially and ethnically diverse). To situate this study, a careful review of the literature was conducted, focusing on recent studies that included ethnically diverse and low-income samples and nonresident as well as resident fathers. This review focuses on studies examining effects of maternal psychiatric disorders and paternal involvement on outcomes for their adolescent child that were published after the large reviews cited in the introductory sentences.

Current research supports prior evidence that maternal depressive symptoms are associated with behavioral problems (externalizing) and depressive, anxious, and socially withdrawing symptoms (internalizing) in youths (Grant et al. 2000; Goosby 2007; Gross et al. 2009). No effect of maternal depressive symptoms was found for youth academic confidence and engagement with school (Seaton and Taylor 2003). Moreover, the previously cited study by Heather Gross and her colleagues (2009) also finds effects over time, strengthening the possibility of a causal argument. Specifically in this study, maternal symptoms of depression were assessed, and then, 3 years later, youths were asked to report on their aggression and delinquent behavior; maternal depression predicted subsequent youth aggression and delinquency. However, these studies do not fully address the population of interest, since all focused on maternal symptoms of depression rather than on maternal SMI (see n. 1).

A precursor to the current study involves assessment of the association between maternal mental health problems and youth academic outcomes. ${ }^{3}$ Mothers were diagnosed with SMI, including schizophrenia, bipolar disorder, and depression. Negative effects of maternal problems in functioning and maternal psychiatric symptoms, including symptoms of depression and of psychosis, were found on youths' subsequent academic outcomes, assessed via school records of grades and teacher 
reports of behavior (Oyserman et al. 2005). In this study, academic outcomes were negatively associated with maternal symptoms and functioning. Outcomes were worse when mothers had more symptoms and functioned at a lower level. This negative effect of maternal mental health problems on academic outcomes was mediated by mothers' lack of parenting confidence (Oyserman et al. 2005).

Although none of the studies reviewed to this point includes information about fathers, a meta-analysis of father involvement effects was conducted by Paul Amato and Joan Gilbreth (1999). The meta-analysis documents a modest but significant and positive association between father involvement and child outcomes. These studies typically obtain child reports of father involvement and find stronger associations between father involvement and child outcomes when children are asked to report on quality rather than quantity of involvement. Because the age range in the studies Amato and Gilbreth (1999) summarized is quite broad, the current review focuses on research that was published after this meta-analysis and that specifically examines associations between father involvement and youth outcomes during the adolescent years. The authors found nine such studies, and their results essentially replicate the earlier finding that higher-quality father involvement is associated with more positive outcomes for youths. Specifically, youths who report higher-quality father involvement also report fewer depressive symptoms and less emotional distress (Salem, Zimmerman, and Notaro 1998; Coley 2003; Stewart 2003), less delinquent involvement (among those previously involved; Coley and Medeiros 2007), less tobacco use (Menning 2006b), less alcohol use (Jordan and Lewis 2005), and better academic outcomes (Nord, Brimhall, and West 1997; King and Sobolewski 2006; Menning 2006a). However, results from these studies differ from the Australian studies previously cited (Brennan et al. 2003; Hammen et al. 2004) in that father involvement is not associated with youth social skills (McCabe, Clark, and Barnett 1999).

\section{Current Study}

Two main-effect and one interaction-effect hypotheses are tested in the current study. The main effects hypotheses are that maternal SMI and father involvement are each associated with youth outcomes separately. The interaction effect hypothesis is that father involvement moderates the negative effects of maternal SMI. Given the scarcity of prior evidence, this study examines but does not hypothesize about the role of the father living arrangement. 


\section{Methods}

Recruitment

Mothers and their adolescent children were recruited in a two-step process after institutional review board approval was obtained. First, a list of eligible mothers was obtained from the management information system client lists of 12 community mental health (CMH) agencies and three inpatient psychiatric units in southeast Michigan. ${ }^{4}$ Next, these mothers were contacted and asked to participate in the Meaning of Motherhood Study that was funded by the National Institute of Mental Health (NIMH; grant R01 54321 to Carol Mowbray and Daphna Oyserman). Participating mothers who had children between the ages of 11 and 18 were asked if their adolescent child could participate in the partner NIMH-funded study, Pathways for Youth (NIMH R01 57495 to Oyserman, Mowbray, and Deborah Bybee). A total of 484 eligible woman were identified, of whom 78 percent participated (12 percent declined participation; 10 percent agreed but could not be contacted or scheduled). Of the participating women, 237 had a child between the ages of 11 and 18; 87 percent permitted an interview with the child. The final mother-youth sample included 168 pairs (27 youths could not be located; 11 were located but declined participation).

\section{Procedure and Sample}

The adolescent sample (age $M=15.01$; $\mathrm{SD}=2.04$ ) was balanced by sex ( $n=88$ males, 80 females) and was racially diverse (58 percent African American, 32 percent non-Hispanic white, 8 percent Hispanic, and 2 percent other), though predominantly African American. Some additional sample characteristics are described in table 1. Of note are maternal diagnosis, family poverty, living arrangements, and presence of fathers. A structured interview protocol yielded the following diagnoses: schizophrenia (20.2 percent), bipolar disorder (23.2 percent), and major affective disorder (56.6 percent). Maternal reports of household income indicate that over half of families lived below the poverty line. About one in 10 (13 percent) youths reported a living arrangement that included both mother and biological father (including joint custody or some other informal arrangement that included both mother and father on a regular basis). About two in 10 youths (22 percent) reported that their biological father lived with them most of the year (termed "resident biological father" in table 1). About three-quarters (76 percent) of youths reported that a father figure was involved in their life, and 39 percent reported that the father figure was the main caregiver or a supplemental caregiver. ${ }^{5}$

Maternal and youth interviews took place over a 5 -year period starting in 1995; mothers were interviewed three times over a period of 3.5 years 
Table 1

Sample Descriptive Information by Category $(N=168$ Mother-Adolescent Pairs)

\begin{tabular}{lc}
\hline & \% or Mean (SD)* \\
\hline Mother: & \\
Race or ethnicity: & 59.5 \\
African American & 6.5 \\
Hispanic & 31.5 \\
White & 2.4 \\
Other & $40.3(5.8)$ \\
Age (mean years, SD) & \\
Diagnosis: & 56.6 \\
Major depressive disorder & 23.2 \\
Bipolar & 20.2 \\
Schizophrenia & 36.9 \\
Educational attainment: & 25.6 \\
Did not complete high school & 37.5 \\
Completed high school or equivalent & 53.0 \\
Completed at least some college courses & \\
Household below the poverty line & 52.4 \\
Adolescent: & \\
Male gender & 57.7 \\
Race or ethnicity: & 5.4 \\
African American & 29.2 \\
Hispanic & 4.2 \\
White & $15.0(2)$ \\
Other & 13.1 \\
Age (mean years, SD) & 22.0 \\
Living arrangement: & 76.2 \\
Included both biological mother and father & 38.7 \\
Resident biological father for most of the year & \\
Father figure present in youth's life & \\
Father figure main or additional caregiver & \\
\hline
\end{tabular}

* Parentheses enclose standard deviations. Unless otherwise specified, results are presented in percentages.

+ Maternal diagnosis: A PhD psychologist trained in the Diagnostic Interview Schedule conducted the interviewer training for administration of this structured protocol and also assigned diagnoses. Differences in diagnostic determinations between the interviewer and the PhD psychologist were identified and discussed to reach a consensus determination.

(42.7 months), with approximately 1.5 years (21.3 months) elapsing between each interview. Youths were interviewed twice. The first youth interview occurred about 1.5 months ( 5.7 weeks) after the last maternal interview, and the second youth interview took place 9 months later.

Before any youth was interviewed, maternal written, informed consent for the child interview was obtained. Then youths were contacted and told that their mothers had participated in a parenting study and had given permission for them to be interviewed. Youths were then invited to participate, and those who assented were interviewed.

Mothers also provided written informed consent to allow the research staff to obtain school records and teacher reports of her child's behavior for the Pathways for Youth study. Adolescents who assented to participate 
were asked the name of a core subject teacher who knew them well and an alternate teacher in case he or she was not able to respond.

Schools were approached with signed consent forms that bore the Pathways for Youth study title. Research staff then requested to input the school record of the child's grade point average. The first nominated teacher was also contacted, shown the signed parental consent form, and asked to provide a report of the listed adolescent's behavior in class. Data were obtained, on average, 5-6 months after the adolescent's interview. When the first nominated teacher was not available or did not respond, the alternate teacher was contacted. Teachers who completed the child in-class behavior checklist were reimbursed $\$ 5$ for their time.

Data from four sources (mothers, youths, teachers, and school records) and six time periods are used in the current analyses. Data were obtained in temporal order as follows: maternal wave 1 (maternal demographics and diagnosis), maternal wave 2 (maternal psychiatric functioning and symptoms) data, youth wave 1 (father involvement, teacher names), youth wave 2 (risky behavior, affiliative skill, internalizing), teacher reported in-class behavior, and school records.

\section{Measures}

For each measure, source and response scale information are listed below. Table 2 provides descriptive statistics and scale reliability information.

\section{Maternal Mental Health Problems}

Maternal Lifetime Psychiatric Diagnoses.-Diagnoses were determined from maternal wave 1 responses to modules from the Diagnostic Interview Schedule (DIS; Robins et al. 1981). The DIS was administered to mothers by trained interviewers who were supervised by an MSW-level interview coordinator and a doctoral-level senior clinical researcher who was extensively trained on the DIS. Diagnostic determinations were based on the DIS interviewer completed form and taped interviews and represented a consensus of the interview coordinator and clinical researcher (for more details, see Mowbray et al. 2004).

In addition to the data on lifetime diagnoses, interviewers obtained information on a number of other measures. While some measures asked participants to reflect on past as well as current experiences, others focused on experiences during the week or month preceding the wave 2 interview, and others used the past year as a reference. In each case, maternal responses were obtained prior to child responses as detailed in the procedure and sample section.

Colorado Symptom Index.-Symptoms of psychosis, anxiety, and depression were assessed using the 14-item Colorado Symptom Index of Depressive and Psychotic Symptomatology (Shern et al. 1994). A mean 
Father Involvement

Table 2

Mean, Standard Deviation, and Scale Reliability

$(N=168$ Mother-Adolescent Pairs $)$

\begin{tabular}{|c|c|c|c|}
\hline & Mean & SD & Alpha \\
\hline \multicolumn{4}{|l|}{ Maternal mental health problems: } \\
\hline \multicolumn{4}{|l|}{ Colorado Symptom Checklist (depressive } \\
\hline or psychotic symptoms) & 2.63 & .74 & .91 \\
\hline CESD-R* (depressive symptoms) & 23.52 & 14.20 & .93 \\
\hline $\begin{array}{l}\text { Hassles and Uplifts Scale (hassles with } \\
\text { daily functioning) }\end{array}$ & 2.04 & .76 & .80 \\
\hline Self-Report Community Functioning & & & \\
\hline (level of daily functioning) & 3.48 & .50 & .80 \\
\hline \multicolumn{4}{|l|}{ 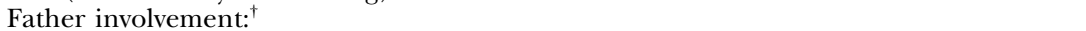 } \\
\hline Helpfulness with personal problems & 1.58 & 1.08 & $\ldots$ \\
\hline Helpfulness with money & 1.85 & 1.19 & $\ldots$ \\
\hline Fun to be with & 1.88 & 1.18 & $\ldots$ \\
\hline Quality of relationship & 2.95 & 1.95 & $\ldots$ \\
\hline \multicolumn{4}{|l|}{ Adolescent risky behavior: } \\
\hline Delinquency $^{+}$ & .23 & .31 & .85 \\
\hline Smoking or drinking & .61 & 1.14 & .67 \\
\hline \multicolumn{4}{|l|}{ Adolescent internalizing behaviors: } \\
\hline \multicolumn{4}{|l|}{ Revised Children's Manifest Anxiety } \\
\hline Scale (symptoms of anxiety) & 7.16 & 5.74 & .88 \\
\hline CESD-R* (depressive symptoms) & 10.09 & 11.09 & .88 \\
\hline Internalizing ${ }^{8}$ & 48.82 & 10.40 & .93 \\
\hline \multicolumn{4}{|l|}{ Adolescent academic outcomes: } \\
\hline Core subject GPA ${ }^{\|}$ & 2.11 & .97 & 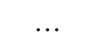 \\
\hline Teacher-rated positive in-class behavior & 3.28 & .88 & .91 \\
\hline Teacher-rated negative in-class behavior & 1.75 & .62 & .77 \\
\hline \multicolumn{4}{|l|}{ Adolescent affiliating skills: } \\
\hline Initiating friendship & 3.37 & .78 & .75 \\
\hline Providing emotional support to friends & 3.57 & .72 & .77 \\
\hline Self-disclosure & 2.72 & .78 & .84 \\
\hline
\end{tabular}

NotE. - CESD-R = Center for Epidemiologic Studies Scale for Depression, Revised (Radloff 1977); GPA = grade point average. Ellipses in the alpha column denote singleitem measures that do not have a reliability score.

* CESD-R is a sum of items with a maximum score of 60; scores above 16 are generally considered indicative of depression.

${ }^{+}$Father involvement is assessed with single items; hence, no alpha can be reported.

${ }^{\ddagger}$ Delinquency scale scores are log transformed (ln) due to high skew (2.95) and kurtosis (12.85) in the original metric. The transformation resulted in $\mathrm{M}=.19, \mathrm{SD}=.21$, skew $=1.75$, kurtosis $=4.09$.

$\$$ Analyses follow the Child Behavior Checklist manual (Achenbach 1991) by summing internalizing item scores and converting them to age-standardized scores, called $T$-scores $(M=50 ; \mathrm{SD}=10)$. The manual provides score guidelines: normal $T$-scores are under 67, borderline clinical $T$-scores are between 67 and 70 , and clinical $T$-scores are above 70

"GPA is from school records for math, science, history, and English.

of item responses is obtained as an indicator of how often in the past year a person has experienced symptoms of psychosis, anxiety, or depression. Example items are "How often do you hear voices, or hear or see things that other people don't think are there?"; "How often do your [voices], thoughts, or feelings interfere with your doing things?"; and "How often do you feel like seriously hurting someone else?" Par- 
ticipants are asked to provide a count of these experiences in the past year, using five response options $(1=$ never, $2=$ once a month or less often, $3=$ several times a month, $4=$ several times a week, and $5=$ at least every day).

Center for Epidemiologic Studies Scale for Depression, Revised Depression Scale.-This scale (CESD-R; Radloff 1977) is used as an indicator of depressive symptoms. This is a 20-item scale, and responses are summed. Example items are "I had trouble keeping my mind on what I was doing," and "I felt like a bad person." Participants were instructed to consider how they felt or behaved in the week preceding the interview and to map their responses onto one of the following five response options ( 1 $=$ rarely or never [less than 1 day], $2=$ some or a little [1-2 days], 3 $=$ occasionally [3-4 days], and $4=$ most or all the time [5-7 days]).

Hassles and Uplifts Scale.-This scale (Lazarus and Folkman 1984) provided an indication of maternal hassles. Hassles were defined in the instructions as "situations or people that can be annoying in minor ways or problematic in fairly major ways. The following is a list of situations that may or may not be hassles in your life." Following the stem "How much of a hassle is . . ." mothers reported on their experienced hassles with "cooking and housework," "shopping," "your health," "your energy level or physical abilities," and "your medication." Participants were asked to rate each of these five items on a four-point response scale (1 $=$ not a hassle at all, $2=$ somewhat of a hassle, $3=$ a moderate hassle, $4=$ a great deal of hassle). A mean hassle score was obtained. Following Richard Lazarus and Susan Folkman (1984), the scale does not specify a time period in which the hassles have been occurring.

Self-Report Community Functioning Scale.-This scale (Bybee et al. 2003) provides an indication of maternal functioning via the mother's report of her behaviors and activities occurring in the month leading up to the interview. The measure was developed specifically for women with SMI living in community settings. (The full 18-item measure is presented in Bybee et al. [2003].) Each item has a relevant response set. For example, the item "In the past month, how often have you felt in control of your feelings and actions?" has the response options of $1=$ hardly ever, $2=$ rarely, $3=$ sometimes, $4=$ most of the time, $5=$ nearly all the time. The item "In the past month, how hard has it been for you to join in conversations?" has the response options of $1=$ you almost never talked with anyone, 2 = you almost never started a conversation, and you had trouble responding, $3=$ you almost never started a conversation, but could respond if someone talked to you, $4=$ you had some trouble starting up a conversation, but you did it sometimes, 5 =you had no trouble starting up a conversation, and you did it frequently. Items address important domains of community life, including managing a household, engaging in productive activity, interacting with friends and family, communicating with other people, controlling one's 
actions and handling crises, maintaining mental and physical health, and avoiding substance abuse. Each item is answered along a five-point scale tailored to the content of the question. In each case, a response of one reflects no activity in the domain, and a response of five reflects frequent independent activity in the domain.

\section{Father Involvement}

Father involvement was assessed in the youth wave 1 interview. Three items from the Social Support Microsystems Scales (Seidman et al. 1995) assessed adolescent's perceptions of the social support received from their father. The items were father's helpfulness with personal problems, helpfulness with money, and how much the father was fun to be with (see table 1). Four response options were provided: $0=$ not applicable; this person is not in my life, $1=$ not at all, $2=$ sort of, $3=$ very. In addition, the quality of the relationship was assessed at the same wave with the following item: "I consider the quality of my relationship with my father to be . . ."; response choices were $0=$ no relationship, $1=$ negative (bad), $2=$ not great, $3=$ neutral, $4=\mathrm{OK}, 5=$ positive $(\operatorname{good}){ }^{6}$

\section{Youth Academic Outcomes}

School records of core (English, math, science, history) academic grade point average (GPA) were obtained for the semester preceding the interview. The GPA was scored as $0=\mathrm{F}, 1=\mathrm{D}, 2=\mathrm{C}, 3=\mathrm{B}$, and $4=\mathrm{A}$.

On a five-point response scale, teachers rated the relative frequency of seven positive school-engaged behaviors such as paying attention in class and participating in class discussion. On the same scale, they rated seven negative school-disruptive behaviors such as bothering classmates and coming late to class. Response options range from $1=$ never to 5 $=$ always (Finn, Pannozzo, and Voelkl 1995). ${ }^{7}$

\section{Youth Mental Health Problems}

In youth wave 2 interviews, measures of youth symptoms of anxiety, depression, and internalizing were obtained to evaluate interviewed adolescents' mental health problems. Level of anxiety is evaluated as the mean of the responses to the 27 items in the Revised Children's Manifest Anxiety Scale (Cole et al. 2000), which has two response options $(1=$ yes, $0=$ no). Level of depressive symptoms is evaluated as the sum of the responses to the 20 items in the CESD-R (Radloff 1977). The CESD-R has four response options, which range from $0=$ never to less than once this past week to $3=$ at least 5 days this week. Level of internalizing is evaluated as the mean of the responses to the 31 items in the Achenbach Child Behavior Checklist, Youth Self-Report Internalizing Subscale 


\section{Social Service Review}

(CBCL; Achenbach 1991). This subscale measures the extent that youths experienced internalizing symptoms in the 6 months prior to the wave 2 child interview. There are three possible responses for each item: "not true" (coded as 0), "somewhat or sometimes true" (coded as 1), and "very true or often true" (coded as 2).

Youth Risky Behavior.-In the youth wave 2 interview, youths reported on their risky behavior in the past 12 months, including 14 items focused on delinquent behavior taken from Delbert Elliot, David Huizinga, and Suzanne Ageton (1985), and three items focused on tobacco and alcohol use from the National Longitudinal Study of Adolescent Health, ADD Health In-Home Questionnaire subscale (1998). Sample delinquency questions include How often in the past year have you "hit a teacher or supervisor at work"? Response options were presented on a five-point scale ranging from $0=$ never to $5=$ five or more times. The tobaccosmoking and alcohol-drinking items also focused on the past 12 months and had a seven-point response scale ranging from $0=$ never to $6=$ nearly every day.

Youth Affiliative Skills. - Three six-item scales from the Adolescent Interpersonal Competence Questionnaire (Kuperminc, Blatt, and Leadbeater 1997) were used to assess youths' affiliative skills in their close relationships with peers. The scales were focused on three domains: initiation of friendships, providing emotional support to friends, and selfdisclosure to friends. Youths were provided with a five-point response scale and could choose responses ranging from 1 (poor at this) to 5 (extremely good at this).

\section{Analysis Plan}

Structural equation modeling was used to test the main and interaction effects of paternal (father involvement) and maternal (mother's mental health problems) factors on youth outcomes and the moderating effect of father involvement on the impact of maternal mental health problems on youth outcomes. Control variables found to be statistically significantly related to youth outcomes in at least one of the reviewed studies were included (e.g., Stewart 2003; Oyserman et al. 2005; Chang et al. 2007). These control variables are youth gender $(1=$ male, $0=$ female $)$, youth racial-ethnic background ( $1=$ African American, $0=$ other), and living arrangement (coded as 1 if the youth lives with his or her mother and father, or if parents have joint custody, or if there is some other living arrangement that regularly includes mother and father; coded as 0 if the father is not regularly part of the youth's living arrangement). Directional paths parallel the timing of data collection (early waves before later waves) and the theoretical model that maternal mental health and father involvement influence youth outcomes.

In the first step, confirmatory factor analysis was used to verify the 
factor structure of the maternal, paternal, and youth constructs. This process was informed by latent measurement models developed in previous analyses of maternal and youth data (Oyserman et al. 2005). Latent constructs were formally tested for factorial invariance using Barbara Byrne, Richard Shavelson, and Bengt Muthén’s (1989) multigroup confirmatory factor analysis method. This is done to insure equivalent structure and meaning across groups that vary in what the father's caregiver status is (i.e., main, additional, or less involved). This step establishes adequate fit and invariance of the measurement models.

Next, structural models were used to test the hypothesized main and interaction effects of maternal mental illness and father involvement on the four youth outcomes. The unconstrained approach is used to model the latent interaction of father involvement and maternal mental illness, as detailed by Herbert Marsh, Zhonglin Wen, and Kit-Tai Hau (2004). Analyses use maximum likelihood methods (AMOS 7.0 software; Arbuckle and Wothke 2006) to estimate model parameters and use the indices and thresholds suggested by Li-tze Hu and Peter Bentler (1998, 1999) to assess model fit. Specifically, the analyses multiply pairs of centered variables, four from the maternal (mother's mental health problems) construct and four from the paternal (father involvement) construct. These pairs, labeled maternal $1 \times$ paternal 1 , maternal $2 \times$ paternal 2, and so on, in figure 1 , are used as indicators of the interaction construct. Because there are four maternal and four paternal indicators, four unique pairs were created, and all indicators are represented in the interaction construct. Because each of the father involvement indicators had similar loadings on the latent paternal construct, the order in which they were paired with the maternal construct indicators is inconsequential (see Marsh et al. 2004).

\section{Results}

\section{Measurement Models}

Confirmatory factor analysis is used to examine the adequacy of the latent constructs in the model. Two measurement models are tested: one with the (father and mother) predictors and one with the (youth) outcomes. The predictor measurement model fits the data well $\left(\chi^{2}=\right.$ 16.14 , df $=19, p=.648$; root mean square error of approximation $[$ RMSEA $]=.000$; comparative fit index $[\mathrm{CFI}]=1.000)$. The outcome measurement model is a marginally adequate fit for the data $\left(\chi^{2}=\right.$ $74.05, \mathrm{df}=38, p=.000$; RMSEA $=.075$; CFI $=.931)$. All indicator loadings in the measurement models are statistically significant. Descriptive statistics (table 2) and bivariate correlations (table 3) are presented for variables used in the measurement and structural models. All correlation coefficients between variables associated with the same 


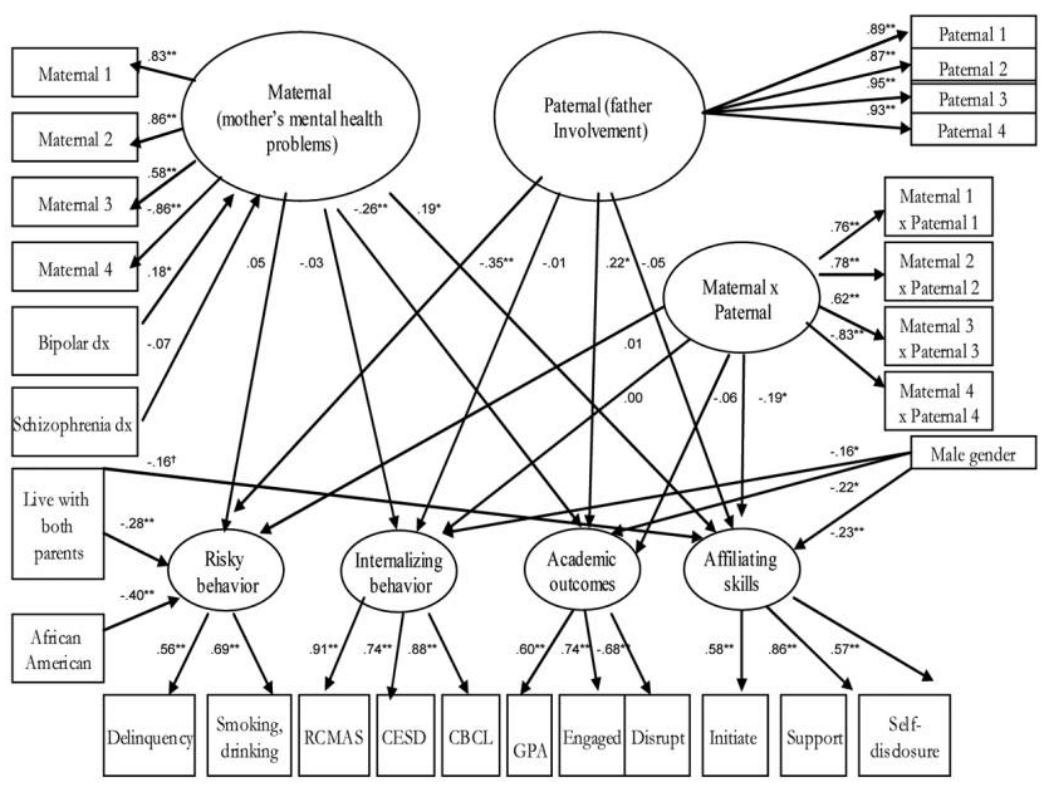

Fig. 1.-Estimated effects of maternal (mother's mental health problems) and paternal (father involvement) factors on adolescent outcomes (risky behavior, internalizing behavior, academic outcomes, and social affiliating skills). Nоте.-Maternal $1=$ Colorado Symptom Checklist; Maternal 2 = Center for Epidemiologic Studies Scale for Depression, Revised (CESD-R); Maternal 3 = Hassles and Uplifts Scale (hassles with daily living); Maternal 4 = Self-Report Community Functioning Scale (level of daily functioning); Paternal 1 = father involvement—helpfulness with personal problems; Paternal 2 = father involvement-helpfulness with money; Paternal 3 = father involvement-fun to be with; Paternal $4=$ father involvement—quality of the relationship. RCMAS $=$ Revised Children's Manifest Anxiety Scale; CBCL = Child Behavior Checklist, Youth Self-Report Internalizing Subscale; GPA = core subject grade point average; Engaged $=$ Finn et al. (1995) scale of teacher-reported positive in-class behavior; Disrupt $=$ Finn et al. (1995) scale of teacher-reported negative in-class behavior; Initiate $=$ Adolescent Interpersonal Competence Questionnaire Initiation of Friendships Subscale; Support = Adolescent Interpersonal Competence Questionnaire Provide Emotional Support to Friends Subscale; Self-Disclose $=$ Adolescent Interpersonal Competence Questionnaire Self-Disclosure to Friends Subscale. $N=168$ mother-youth pairs $\left(\chi^{2}=424.71, \mathrm{df}=325, p=.000\right.$, RMSEA $-.043)$. All coefficients are standardized. Significance: $*=p<.05, * *=p<.01, \dagger=p$ $<.10$.

latent construct are statistically significant and substantially higher than the correlations of these variables with variables associated with other constructs.

\section{Structural Model}

Figure 1 illustrates the structural model. For clarity, some correlations are reported in table 4 rather than in the figure. The omitted correlations are the correlation between the latent maternal and paternal constructs; the correlations among the latent youth constructs; and cor- 


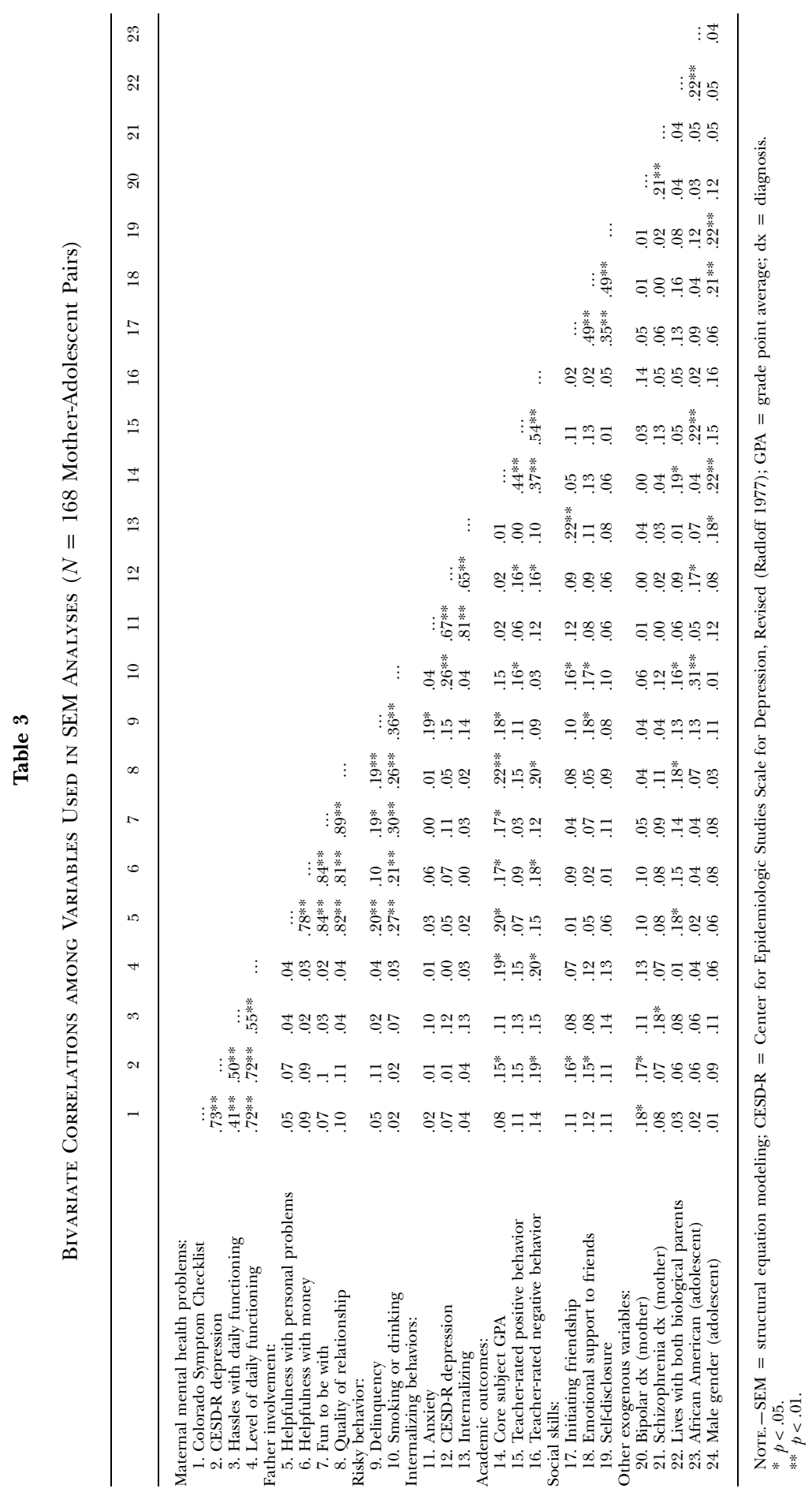


Table 4

Correlated Error Modeled in SEM Analyses

$(N=168$ Mother-Adolescent Pairs $)$

\begin{tabular}{lc}
\hline Correlated Error & $R$ \\
\hline $\begin{array}{l}\text { Maternal (mother's mental health problems) paternal } \\
\quad(\text { father involvement) }\end{array}$ & .13 \\
Bipolar dx schizophrenia dx & $-.21^{* *}$ \\
African American living arrangement & $-.22^{* *}$ \\
Living arrangement paternal (father involvement) & $.17^{*}$ \\
Risky behavior internalizing behaviors & $.31^{*}$ \\
Risky behavior academic outcomes & -.15 \\
Risky behavior affiliating skills & $.34^{*}$ \\
Internalizing behaviors academic outcomes & -.16 \\
Internalizing behaviors affiliating skills & .05 \\
Academic outcomes affiliating skills & .19 \\
\hline
\end{tabular}

NoтE. $-\mathrm{SEM}=$ structural equation modeling; $\mathrm{dx}=$ diagnosis.

$* p<.05$.

$* * \quad p<.01$

relations among the living arrangement item, the race item, and the latent paternal construct. The statistically significant chi square indicates that model fit is imperfect, but generally accepted fit index thresholds suggest that fit is adequate $\left(\chi^{2}=424.710, \mathrm{df}=325, p=.000\right.$; RMSEA $=.043$; CFI $=.947)$. In the figure, asterisks identify statistically significant coefficients, and a dagger $(\dagger)$ identifies the coefficient that is significant at trend level $(p<.10)$. Preliminary analyses looked for but did not find a direct effect of maternal diagnosis on youth outcomes.

Direct effects of the maternal construct (mother's mental health problems).- The maternal (mother's mental health problems) construct is a statistically significant and negative predictor of youth academic outcomes $(\beta=-.26, p=.007)$ and a statistically significant and positive predictor of youth affiliative skills $(\beta=.19, p=.037)$. No statistically significant association between the maternal construct and youth risky or internalizing behaviors is found.

Direct effects of the paternal (father involvement) construct.-The paternal (father involvement) construct is a statistically significant and positive predictor of youth academic outcomes $(\beta=.22, p=.015)$ and a statistically significant and negative predictor of youth risky behavior $(\beta=$ $-.35, p=.001)$. No statistically significant association between the paternal construct and youth internalizing behaviors or affiliative skills is found.

Maternal and paternal construct interaction: Moderating effect of father involvement. - The maternal $\times$ paternal interaction construct is included in the model to test the moderating effect of father involvement. The interaction construct is a statistically significant and negative predictor 


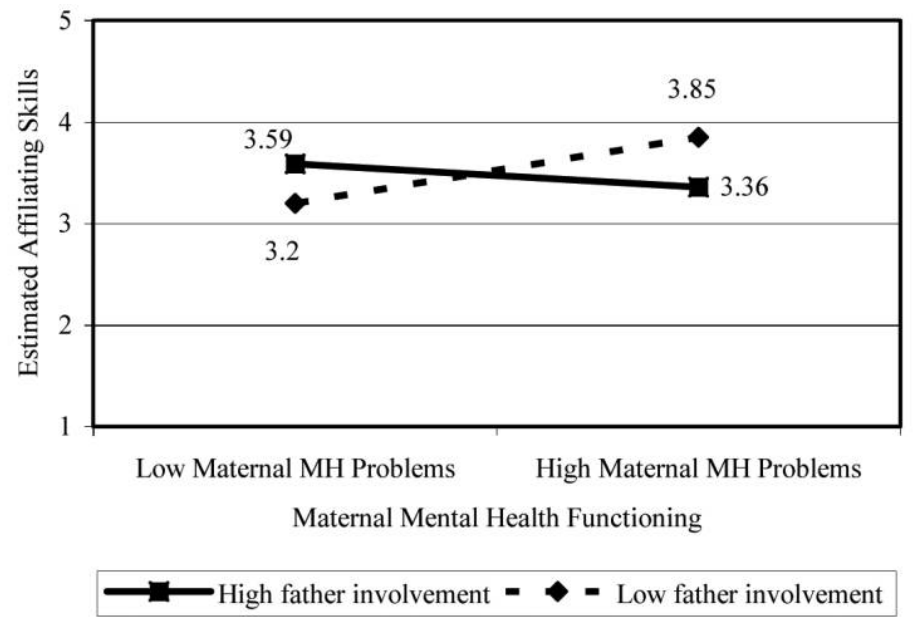

Fig. 2.-Effect of maternal mental health problems on youth affiliative skills. Note.$\mathrm{MH}=$ mental health.

of youth affiliative skills $(\beta=-.19, p=.041)$. This interaction is depicted graphically in figure 2 and shows that the maternal (mother's mental health problems) construct is statistically significantly associated with higher youth affiliative skills when the paternal (father involvement) construct is low, not otherwise. Calculation of the interaction effect's 95 percent region of significance (not shown) clarifies that the maternal construct (mother's mental health problems) is significantly associated with higher youth affiliative skills only when father involvement is lower than .043, a level that is slightly above the centered mean of 0.00 .

Effects of covariates. - Gender, race, and living arrangements are associated with youth outcomes. Compared to girls, boys report less internalizing behavior $(\beta=-.16, p=.042)$ and less competence in close relationships with peers $(\beta=-.23, p=.009)$. Schools and teachers report worse grades and behavior for boys than girls $(\beta=-.22, p=$ .015). Compared to non-African American youths, African American youths are statistically significantly less likely to report engaging in risky behavior $(\beta=-.40, p=.000)$; they are also statistically significantly less likely to have a living arrangement that regularly includes both biological parents $(r=-.22, p=.007)$. Youths with such arrangements are statistically significantly less likely to report risky behavior $(\beta=-.28$, $p=.006$ ) than are youths whose father is not part of the regular living arrangement, and they report less competence in close relationships with peers, though this latter effect is statistically significant only at trend level $(\beta=-.16, p=.077)$. Father involvement is also higher in house- 
holds where both parents are part of the regular living arrangement than in households where the father is not part of the regular arrangement $(r=.17, p=.031)$.

\section{Discussion}

The study considers the main and interaction effects of maternal (mother's mental health problems) and paternal (father involvement) factors in a sample of low-income, racially and ethnically diverse motheradolescent pairs in which all mothers were diagnosed with an SMI. Previous research suggests that father involvement is associated with positive youth outcomes (Brennan et al. 2003; Hammen et al. 2004; Carlson 2006; Chang et al. 2007). Finding evidence of such associations in the current sample would have important implications for intervention, particularly because the adolescent children of mothers with serious mental health problems are at risk of problematic outcomes (Oyserman et al. 2000).

The current analyses estimate the influence of paternal (father involvement) and maternal (mother's mental health problems) factors across a spectrum of youth outcomes: academic performance, engagement in risky behavior, internalizing symptoms, and affiliative skills. Father involvement is assessed from the youth's perspective, which is typical in this literature (see Brennan et al. 2003; Hammen et al. 2004; Carlson 2006; Chang et al. 2007). Additionally, youths reported on their living situation and whether living arrangements typically included the father. Maternal diagnosis was assessed separately from maternal symptoms, level of functioning, and hassles with functioning.

As is generally true among families in which mothers have an SMI (Mowbray et al. 1995; Oyserman et al. 2000), most fathers in the current study did not live at home. The level of father involvement does vary, however, and this variability provides a sufficient range to test the possibility that father involvement matters for youth outcomes, separate from whether the father lives at home with the youth. All mothers had an SMI (defined as a long-term, persistent mental illness that encompasses diagnostic categories of major affective disorders, schizophrenia, and related disorders combined with utilization of intensive forms of mental health services for a period of more than 1 year). However, they varied in the levels of symptoms and functioning at the time of the interview (with symptoms and functioning operationalized as psychotic and depressive symptoms, hassles with functioning, and level of community functioning). This variability allows for examination of the influence of both maternal diagnosis and current mental health problems. By contrast, analyses of community-based samples typically focus on depressive symptoms alone.

Current findings are both congruent with and supplemental to prior 
research. Maternal diagnosis is not itself directly associated with youth outcomes, but it has an indirect effect because maternal bipolar disorder is positively associated with the maternal construct (maternal mental health problems). In the current analyses, the paternal construct (father involvement) is not statistically significantly correlated with either maternal mental health diagnosis or the maternal construct (maternal mental health problems). The authors interpret this to mean that father involvement does not depend on the nature of maternal mental health problems; since father involvement does vary, it must depend on other factors. These factors may include child outcomes, since the current analyses cannot rule out the possibility that fathers are more involved with more successful children.

There are three key results of the analyses of maternal and paternal effects on child outcomes. First, both maternal (mother's mental health problems) and paternal (father involvement) factors are statistically significantly associated with youth academic performance. Second, the paternal (father involvement) factor is statistically and negatively associated with youth risky behavior. Third, there is a direct effect of the maternal factor on youth academic outcomes as well as a significant maternal $x$ paternal interaction effect on youth affiliative skill. Each of these effects is interpreted below.

The negative association of academic outcomes with mother's mental health problems and the positive association with father involvement can be interpreted to mean that adolescent children fare worse in school when mothers have mental health problems and better in school when fathers are involved in their lives. Youths attain better academic outcomes (better grades, less negative and more positive in-school behavior) when their mothers function better, feel less hassled by daily living, and have fewer and less severe symptoms, and also when their fathers are more supportive and involved. The negative association of father involvement on youth engagement in risky behaviors can be interpreted to mean that adolescent children are at lower risk of delinquency, smoking, and drinking alcohol when their father is involved in their lives. These maternal and paternal main effects on youth academic and risky behavior outcomes are not moderated; that is, at least in the current sample and with the current measures, high paternal involvement does not compensate for maternal mental health problems, and maternal mental health problems do not undermine the effect of high paternal involvement. These father involvement results are congruent with other research that examined the effect of father involvement in the context of maternal symptoms of depression, though in this prior research father involvement was more beneficial when the father resided in the home (Carlson 2006).

The effect of the maternal factor and of the maternal $\times$ paternal interaction factor on youth affiliative skills can be interpreted in two 
different ways. It may mean that youths who need to seek support outside the family (since their mothers score high on mental health problems and their fathers score low on involvement) have more friendship skills. Alternatively, it may mean that youths whose mother and father do not provide successful models of competence in close relationships (given poor maternal functioning and low father involvement) rate themselves as comparatively better at affiliative skills. This self-report measure does not allow definitive interpretation of meaning; it is possible that youths had higher skills when these skills were sorely needed because neither mother (given her functioning and symptoms) nor father (given his low involvement) could provide support. Alternatively, it is also possible that youths perceived themselves to be more skillful when comparing themselves to their low-functioning and highly symptomatic mother and their rarely available father.

Gender, race, and living arrangements are also associated with some of the youth outcome variables as detailed next. Being male is associated with statistically significantly elevated risk of poor school outcomes. Being African American and having a consistently present father are associated with statistically significantly reduced risk of engaging in risky behavior.

No statistically significant influence of maternal or paternal factors on youth internalizing symptoms and behaviors is found in the current study. At first, this null result appears incongruent with prior research, since this previous research finds an association between maternal factors (diagnosis and symptoms of depression) and child outcomes (youth internalizing symptoms and problem behaviors; Grant et al. 2000; Burt et al. 2005; Goosby 2007). However, the effects of maternal depression on youths appear to be mediated by family socioeconomic environment (Burt et al. 2005). This implies that the separate effects of maternal depression may have been difficult to find in the high poverty sample used in the current analyses.

The effects of maternal mental health problems on their children's feelings of depression and anxiety may also be difficult to document in this high-risk sample. Three possibilities are documented in the prior literature. First, the influence of maternal mental health problems on youths may be mediated by other factors (e.g., her parenting style). Second, the influence of maternal mental health problems on youths may involve an interaction between her symptoms and her functioning. Third, the influence of maternal mental health problems on youths may be discernible only later in life.

For example, separate analyses with different samples of youths suggest that symptoms of anxiety and depression are associated with parenting style and with low daily functioning combined with few overt symptoms of depression (Oyserman, Bybee, and Mowbray 2002; Oyserman et al. 2005). Maternal data in this study were collected 2 years 
prior to child data, bolstering a possible causal interpretation. Oyserman and her colleagues interpret results as follows: children are more vulnerable to anxiety and depression in response to the combination of low maternal functioning and low maternal symptoms because maternal symptoms provide a clear rationale for maternal behavior (and higher maternal functioning would have been a protective factor; Oyserman et al. 2002). A separate analysis also found that laissez-faire parenting predicts worse academic outcomes 5 years later (Oyserman et al. 2005). Moreover, separate analyses focusing on adult children of mothers with SMI show that as adults, children have high rates of mental health problems and legal problems and that risk of problems is higher when mothers have a diagnosis of bipolar disorder rather than a diagnosis of depression or schizophrenia (Mowbray et al. 2006). Finally, it is possible that changes in maternal functioning influence the mother's parenting (see Kahng et al. 2008) but do not influence her children's risk of internalizing symptoms and behaviors because this risk is predicated on maternal diagnosis, not on functioning.

Another possibility that the authors looked for but did not find is that father involvement might moderate the relationship between maternal mental health problems and youth internalizing. Such a moderating effect was found in community samples in which maternal mental health problems focused on depressive symptoms (Brennan et al. 2003; Hammen et al. 2004). This disjuncture in results suggests that distinguishing depressive symptoms from functioning of women with SMI might be useful in future research and adds to prior research noting lack of focus on the unique needs of low-income mothers in the delivery of mental health services (Oyserman, Mowbray, and Zemencuk 1994).

Taken together, the current results suggest maternal mental health problems and father involvement have separate effects on the outcomes of their children. These findings are important because they suggest that when mothers have serious mental health problems, fathers can play an important role in the lives of their adolescent children even if they do not live with their children. Results and effect sizes are congruent with research that uses community and general population samples (e.g., Stewart 2003; King and Sobolewski 2006; Coley and Medeiros 2007). This congruence suggests that the positive effect of father involvement is not overwhelmed by the severity of the mental health problems of the mothers in the current sample.

The results of this study have several implications for social work practice and policy. First, because father involvement effects are found even though most adolescents do not reside with their fathers, the results argue for interventions that support positive father involvement in their adolescents' lives, whether or not fathers live with their children. Second, because both maternal mental health problems and lack of father involvement are strongly associated with worse youth academic out- 
comes, the results argue for interventions that support youth academic outcomes. Academic success is a critical building block to adulthood careers and therefore to future housing, employment, and stable family life. Therefore, interventions are warranted that can bolster youth academic success and buffer youths' academic success from the negative consequences of low parent involvement in school (see Oyserman, Brickman, and Rhodes 2007). What is not clear from the data is how such intervention should be carried out. It is possible that intervention should focus on mothers (e.g., improving their functioning), on fathers (e.g., improving their involvement), or on the child to bolster motivation, persistence, and engagement with school separate from the home environment (e.g., school-based preventive intervention; Oyserman, Terry, and Bybee 2002; Oyserman, Bybee, and Terry 2006). Finally, more research is needed to understand how nonoptimal circumstances, such as maternal mental illness and lack of father involvement, may trigger the development of affiliative skills and other personal resources that could serve a protective function for some youths.

\section{References}

Achenbach, Thomas M. 1991. Manual for the Youth Self-Report and 1991 Profile. Burlington: University of Vermont, Department of Psychiatry.

Amato, Paul R., and Joan G. Gilbreth. 1999. "Nonresident Fathers and Children's WellBeing: A Meta-Analysis." Journal of Marriage and the Family 61 (3): 557-73.

Arbuckle James L., and Wer Wothke. 2006. AMOS 7.0 computer software. Smallwaters, Chicago.

Beardslee, William R., Eve M. Versage, and Tracy R. Gladstone. 1998. "Children of Affectively Ill Parents: A Review of the Past 10 Years." Journal of the American Academy of Child and Adolescent Psychiatry 37 (11): 1134-41.

Brennan, Patricia A., Robyne Le Brocque, and Constance Hammen. 2003. "Maternal Depression, Parent-Child Relationships, and Resilient Outcomes in Adolescence.” Journal of American Academy of Child and Adolescent Psychiatry 42 (12): 1469-77.

Burt, Keith B., Manfred H. M. van Dulmen, Jill Carlivati, Byron Egeland, L. Alan Sroufe, David R. Forman, Karen Appleyard, and Elizabeth A. Carlson. 2005. "Mediating Links between Maternal Depression and Offspring Psychopathology: The Importance of Independent Data." Journal of Child Psychology and Psychiatry 46 (5): 490-99.

Bybee, Deborah, Carol T. Mowbray, Daphna Oyserman, and Lisa Lewandowski. 2003. "Variability in Community Functioning of Mothers with Serious Mental Illness." Journal of Behavioral Health Services and Research 30 (3): 269-89.

Byrne, Barbara M., Richard J. Shavelson, and Bengt Muthén. 1989. "Testing for the Equivalence of Factor Covariance and Mean Structures: The Issue of Partial Measurement Invariance." Psychological Bulletin 105 (3): 456-66.

Carlson, Marcia J. 2006. "Family Structure, Father Involvement, and Adolescent Behavioral Outcomes." Journal of Marriage and Family 68 (1): 137-54.

Chang, Jen Jen, Carolyn T. Halpern, and Jay S. Kaufman. 2007. "Maternal Depressive Symptoms, Father's Involvement, and the Trajectories of Child Problem Behaviors in a US National Sample." Archives of Pediatrics and Adolescent Medicine 161 (7): 697-703.

Cole, David A., Kit Hoffman, Jane M. Tram, and Scott E. Maxwell. 2000. "Structural Differences in Parent and Child Reports of Children's Symptoms of Depression and Anxiety." Psychological Assessment 12 (2): 174-85.

Coley, Rebekah Levine. 2003. "Daughter-Father Relationships and Adolescent Psychosocial Functioning in Low-Income African American Families." Journal of Marriage and Family 65 (4): 867-75. 
Coley, Rebekah Levine, and Bethany L. Medeiros. 2007. "Reciprocal Longitudinal Relations between Nonresident Father Involvement and Adolescent Delinquency." Child Development 78 (1): 132-47.

Downey, Geraldine, and James C. Coyne. 1990. "Children of Depressed Parents: An Integrative Review." Psychological Bulletin 108 (1): 50-76.

Elliot, Delbert S., David Huizinga, and Suzanne S. Ageton. 1985. Explaining Delinquency and Drug Use. Thousand Oaks, CA: Sage.

Finn, Jeremy D., Gina M. Pannozzo, and Kristin E. Voelkl. 1995. "Disruptive and InattentiveWithdrawn Behavior and Achievement among Fourth Graders." Elementary School Journal 95 (5): 421-34.

Foster, Cynthia Ewell, Melissa C. Webster, Myrna M. Weissman, Daniel J. Pilowsky, Priya J. Wickramaratne, A. John Rush, Carroll W. Hughes, et al. 2008. "Course and Severity of Maternal Depression: Associations with Family Functioning and Child Adjustment." Journal of Youth and Adolescence 37 (8): 906-16.

Gelfand, Donna M., and Douglas M. Teti. 1990. "The Effects of Maternal Depression on Children." Clinical Psychology Review 10 (3): 329-53.

Goodman, Sherryl H., and Ian H. Gotlib. 1999. "Risk for Psychopathology in the Children of Depressed Mothers: A Developmental Model for Understanding Mechanisms of Transmission." Psychological Review 106 (3): 458-90.

Goosby, Bridget. 2007. "Poverty Duration, Maternal Psychological Resources, and Adolescent Socioemotional Outcomes." Journal of Family Issues 28 (8): 1113-34.

Grant, Kathryn, LaShaunda Poindexter, Trina Davis, Mi Hyon Cho, Anthony McCormick, and Kevin Smith. 2000. "Economic Stress and Psychological Distress among Urban African American Adolescents: The Mediating Role of Parents." Journal of Prevention and Intervention in the Community 20 (1-2): 25-36.

Gross, Heather E., Daniel S. Shaw, Rebecca A. Burwell, and Daniel S. Nagin. 2009. "Transactional Processes in Child Disruptive Behavior and Maternal Depression: A Longitudinal Study from Early Childhood to Adolescence." Development and Psychopathology 21 (1): 139-56.

Hammen, Constance, Patricia A. Brennan, and Josephine H. Shih. 2004. "Family Discord and Stress Predictors of Depression and Other Disorders in Adolescent Children of Depressed and Nondepressed Women." Journal of the American Academy of Child and Adolescent Psychiatry 43 (8): 994-1002.

$\mathrm{Hu}, \mathrm{Li}$-tze, and Peter M. Bentler. 1998. "Fit Indices in Covariance Structure Modeling: Sensitivity to Underparameterized Model Misspecification." Psychological Methods 3 (4): 424-53.

- 1999. "Cutoff Criteria for Fit Indexes in Covariance Structure Analysis: Conventional Criteria versus New Alternatives." Structural Equation Modeling 6 (1): 1-55.

Jordan, Lisa C., and Melissa L. Lewis. 2005. "Paternal Relationship Quality as a Protective Factor: Preventing Alcohol Use among African American Adolescents." Journal of Black Psychology 31 (2): 152-71.

Kahng, Sang Kyoung, Daphna Oyserman, Deborah Bybee, and Carol T. Mowbray. 2008. "Mothers with Serious Mental Illness: When Symptoms Decline Does Parenting Improve?" Journal of Family Psychology 22 (1): 162-66.

King, Valarie, and Juliana Sobolewski. 2006. "Nonresident Fathers' Contributions to Adolescent Well-Being." Journal of Marriage and Family 68 (3): 537-57.

Kuperminc, Gabriel P., Sidney J. Blatt, and Bonnie J. Leadbeater. 1997. "Relatedness, SelfDefinition, and Early Adolescent Adjustment." Cognitive Therapy and Research 21 (3): 301-20.

Lazarus, Richard S., and Susan Folkman. 1984. Stress, Appraisal, and Coping. New York: Springer.

Marsh, Herbert W., Zhonglin Wen, and Kit-Tai Hau. 2004. "Structural Equation Models of Latent Interactions: Evaluation of Alternative Estimation Strategies and Indicator Construction." Psychological Methods 9 (3): 275-300.

McCabe, Kristen M., Rodney Clark, and Douglas Barnett. 1999. "Family Protective Factors among Urban African American Youth." Journal of Clinical Child Psychology 28 (2): 137-50.

Menning, Chadwick L. 2006a. "Nonresident Fathering and School Failure." Journal of Family Issues 27 (10): 1356-82. 
2006b. "Nonresident Fathers' Involvement and Adolescents' Smoking." Journal of Health and Social Behavior 47 (1): 32-46.

Mowbray, Carol T., Deborah Bybee, Leslie Hollingsworth, Sara Goodkind, and Daphna Oyserman. 2005. "Living Arrangements and Social Support: Effects on the Well-Being of Mothers with Mental Illness." Social Work Research 29 (1): 41-55.

Mowbray, Carol T., Deborah Bybee, Daphna Oyserman, Paula Allen-Meares, Peter MacFarlane, and Tamera Hart-Johnson. 2004. "Diversity of Outcomes among Adolescent Children of Mothers with Mental Illness." Journal of Emotional and Behavioral Disorders 12 (4): 206-21.

Mowbray, Carol T., Deborah Bybee, Daphna Oyserman, Peter MacFarlane, and Nicholas Bowersox. 2006. "Psychosocial Outcomes for Adult Children of Parents with Severe Mental Illnesses: Demographic and Clinical History Predictors." Health and Social Work 31 (2): 99-108.

Mowbray, Carol T., and Daphna Oyserman. 2003. "Families with Parental Mental Illness, Adolescence." 471-79 in Encyclopedia of Primary Prevention and Health Promotion, edited by Thomas P. Gullotta and Martin Bloom. New York: Kluwer Academic/Plenum.

Mowbray, Carol T., Daphna Oyserman, Judith K. Zemencuk, and Scott R. Ross. 1995. "Motherhood for Women with Serious Mental Illness: Pregnancy, Childbirth, and the Postpartum Period." American Journal of Orthopsychiatry 65 (1): 21-38.

National Longitudinal Study of Adolescent Health. 1998. "In-Home Questionnaire Codebook." http://www.cpc.unc.edu/projects/addhealth/codebooks.

Nord, Christine Winquist, DeeAnn Brimhall, and Jerry West. 1997. Father's Involvement in Their Children's Schools. Statistical Analysis Report no. NCES 98-091. Washington, DC: U.S. Department of Education, National Center for Education Statistics.

Oyserman, Daphna, Daniel Brickman, and Marjorie Rhodes. 2007. "School Success, Possible Selves, and Parent School Involvement." Family Relations 56 (5): 479-89.

Oyserman, Daphna, Deborah Bybee, and Carol T. Mowbray. 2002. "Influences of Maternal Mental Illness on Psychological Outcomes for Adolescent Children." Journal of Adolescence 25 (6): 587-602.

Oyserman, Daphna, Deborah Bybee, Carol T. Mowbray, and Tamera Hart-Johnson. 2005. "When Mothers Have Serious Mental Health Problems: Parenting as a Proximal Mediator." Journal of Adolescence 28 (4): 443-63.

Oyserman, Daphna, Deborah Bybee, and Kathy Terry. 2006. "Possible Selves and Academic Outcomes: How and When Possible Selves Impel Action.” Journal of Personality and Social Psychology 91 (1): 188-204.

Oyserman, Daphna, Carol T. Mowbray, Paula Allen-Meares, and Kristen B. Firminger. 2000. "Parenting among Mothers with a Serious Mental Illness." American Journal of Orthopsychiatry 70 (3): 296-315.

Oyserman, Daphna, Carol T. Mowbray, and Judith K. Zemencuk. 1994. "Resources and Supports for Mothers with Severe Mental Illness.” Health and Social Work 19 (2): 132-42.

Oyserman, Daphna, Kathy Terry, and Deborah Bybee. 2002. "A Possible Selves Intervention to Enhance School Involvement." Journal of Adolescence 25 (3): 313-26.

Radloff, Lenore S. 1977. "The CES-D Scale: A Self-Report Depression Scale for Research in the General Population." Applied Psychological Measurement 1 (3): 385-401.

Robins, Lee N., John E. Helzer, Jack L. Croughan, and Kathryn S. Ratcliff. 1981. "National Institute of Mental Health Diagnostic Interview Schedule: Its History, Characteristics, and Validity." Archives of General Psychiatry 38 (4): 381-89.

Salem, Deborah A., Marc A. Zimmerman, and Paul C. Notaro. 1998. "Effects of Family Structure, Family Process, and Father Involvement on Psychosocial Outcomes among African American Adolescents." Family Relations 47 (4): 331-41.

Seaton, Eleanor, and Ronald D. Taylor. 2003. "Exploring Familial Processes in Urban, LowIncome African American Families." Journal of Family Issues 24 (5): 627-44.

Seidman, Edward, LaRue Allen, J. Lawrence Aber, Christina Mitchell, Joanna Feinman, Hirokazu Yoshikawa, Katherine Anne Comtois, et al. 1995. "Development and Validation of Adolescent-Perceived Microsystem Scales: Social Support, Daily Hassles, and Involvement." American Journal of Community Psychology 23 (3): 355-88.

Shern, David L., Nancy Z. Wilson, Anita Saranga Coen, Diane C. Patrick, Mark Foster, David A. Bartsch, and Jean Demmler. 1994. "Client Outcomes II: Longitudinal Client Data from the Colorado Treatment Outcome Study.” Milbank Quarterly 72 (1): 123-48. 
Stewart, Susan D. 2003. "Nonresident Parenting and Adolescent Adjustment: The Quality of Nonresident Father-Child Interaction." Journal of Family Issues 24 (2): 217-44.

\section{Notes}

Data collection for the reported studies was funded by two grants from the National Institutes of Health (NIMH R01 54321 [Mowbray, principal investigator (PI), Oyserman, coprincipal investigator (co-PI)]; and NIMH R01 MH57495 [Oyserman, PI, Mowbray and Bybee, co-PIs, and Allen-Meares, coinvestigator]). We thank the staff of both projects as well as all the participating family members. Correspondence should be addressed to Daphna Oyserman, Institute for Social Research, University of Michigan, 426 Thompson, Ann Arbor, MI 48109-1248. E-mail: daphna.oyserman@umich.edu.

1. Order of authorship is presented alphabetically and does not represent relative contribution.

2. Serious mental illness refers to long-term, persistent mental illness, usually encompassing diagnostic categories of schizophrenia and related disorders plus major affective disorders, combined with utilization of intensive forms of mental health services for a period of more than 1 year. The term "seriously mentally ill" is preferred over the frequently used "chronically mentally ill" by psychiatric consumer groups (Mowbray et al. 1995).

3. This was conducted as a pilot to the current study and does not include any of the same children.

4. These mothers were eligible because, according to CMH records, they were diagnosed with an SMI (operationalized as schizophrenia, major affective disorder, or bipolar disorder, having duration of greater than 1 year and causing major dysfunction in one or more life areas) and were care giving for at least one child between the ages of 4 and 16 years. When recruitment took place in an inpatient setting, mothers were not interviewed until they had been back in the community for at least a month and had resumed caregiving responsibility for their children (see Kahng et al. 2008). Before recruitment could begin, institutional review board approval from the University of Michigan and the community mental health system was obtained by one of the authors (Oyserman).

5. Although not the focus of the current analyses, mothers provided extensive information on their education, income, and poverty; a more detailed description of the sample is available in other publications about this sample (e.g., Kahng et al. 2008).

6. Maternal report of father caregiver status was also obtained in the youth wave 1 interview. Responses were scored as $1=$ father or stepfather identified as main or additional caregiver $(n=65)$, and $0=$ father or stepfather was not main or additional caregiver $(n=99)$. Note that this measure was not used as an indicator of father involvement in the final model, but, rather, it was used to test for factorial invariance in the father involvement construct. Father's caregiver status was also initially included as a covariate but then dropped since it was not significantly related to the outcome measures.

7. The scales were originally developed for elementary school students; they were revised by its creators for use with middle- and high-school students (Jeremy Finn, personal communication, October 14, 1998). 